\title{
Conforto térmico propiciado por algumas espécies arbóreas: avaliação do raio de influência através de diferentes índices de conforto
}

Thermal comfort offered by certain tree species: evaluation of the radius of influence through different comfort indices

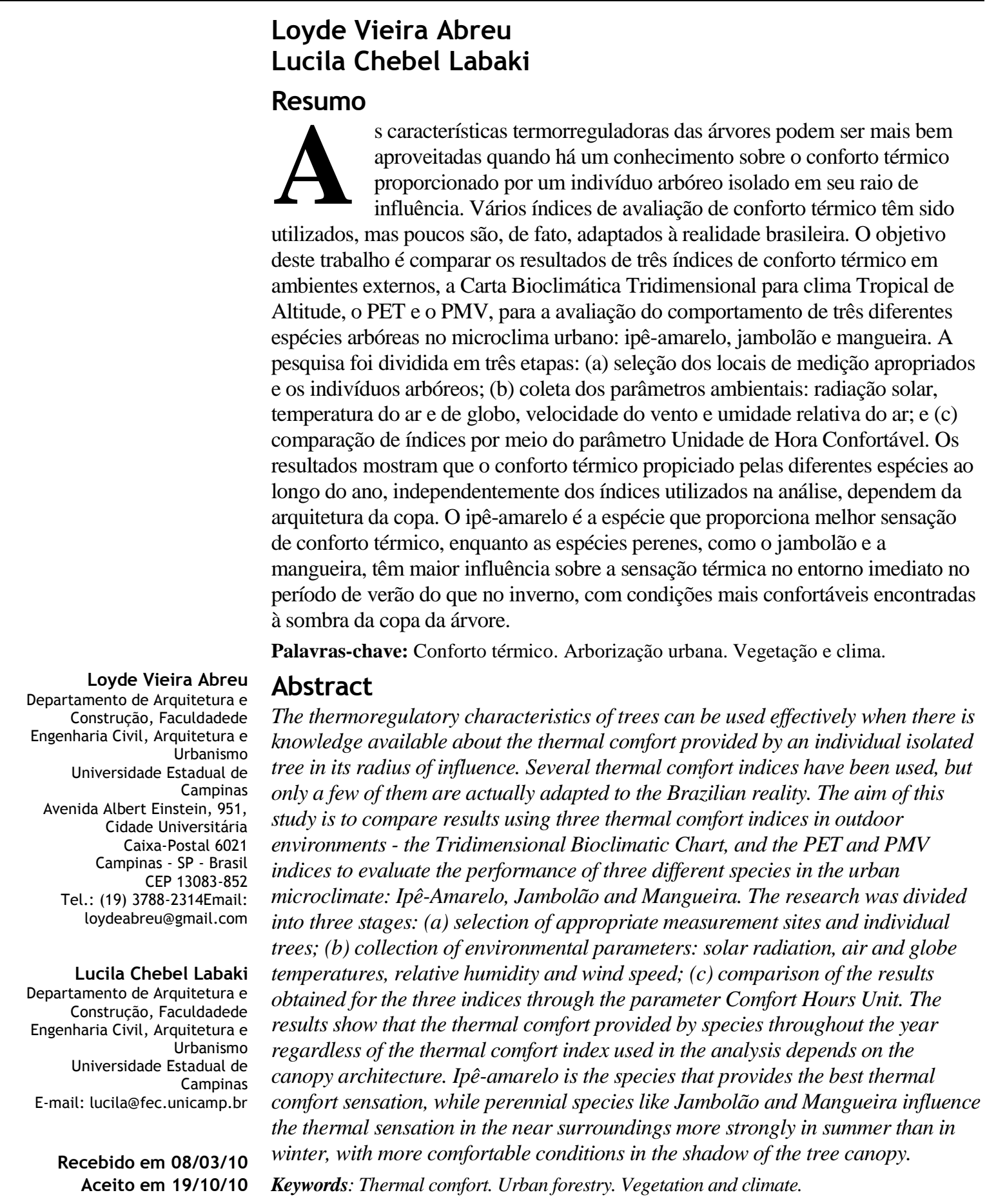




\section{Introdução}

Várias pesquisas utilizando metodologias diversas comprovaram que a vegetação atua sobre o microclima urbano, contribuindo significativamente para melhorar a sensação de bem-estar aos usuários (ABREU; LABAKI, 2008; BUENO, 1998; BUENO-BARTHOLOMEI, 2003; GULYÁS; UNGER; MATZARAKIS, 2006; MONTEIRO; ALUCCI, 2008; MORENO; NOGUCHI; LABAKI, 2007; PEZZUTO; LABAKI, 2007; SANTAMOURIS, 2001). Porém, existem poucos estudos comparativos que analisam o índice de conforto térmico mais adequado para se avaliarem ambientes externos, numa escala microclimática, considerando a realidade brasileira.

Gulyás, Unger e Matzarakis (2006) determinaram o conforto térmico através dos índices PET e PMV em espaços abertos, praças e ruas de Freiburg, Alemanha, e verificaram que as árvores criam características especiais numa escala microclimática. Spangenberg et al. (2007) constataram a influência benéfica das árvores no microclima urbano através dos resultados do PET em um estudo sobre praças de São Paulo, Brasil. Várias pesquisas realizadas no Brasil adotaram o PET, índice adaptado à realidade europeia que, provavelmente, não expressa a real sensação de conforto térmico do usuário local. Por isso, Monteiro e Alucci (2008) destacam a importância do estabelecimento de uma base empírica mais significativa, que possibilite a interpretação cruzada dos dados obtidos em diferentes pesquisas, para um adequado mapeamento das relações entre microclimas e usuários nas diferentes regiões do Brasil.

Katzschner, Bosch e Rvttgen (2002) e Nikolopoulou (2002) avaliaram as condições de conforto térmico em ambientes abertos em diferentes cidades europeias, através do índice de conforto PMV, e verificaram que nem sempre há uma forte correlação entre o índice e a sensação das pessoas.

Os climas e microclimas de áreas externas no meio urbano localizados em diferentes latitudes sugerem índices de conforto térmico igualmente distintos, pois estes não estão associados somente às características ambientais, mas também às populacionais. A sensação térmica experimentada pela população em determinado local é a base para a definição do intervalo das variáveis ambientais que compõem uma zona de conforto, sensação esta definida pelas respostas físicas, fisiológicas e psicológicas (MORENO; NOGUCHI; LABAKI, 2007).
A partir de entrevistas, Ahmed (2003) estudou várias conformações urbanas que favorecem o conforto na área externa e estabeleceu um critério de zona de conforto em área tropical urbana no verão, para pessoas envolvidas em atividade de 1 Met (sedentária) e usando vestimenta com resistência térmica de 0,35-0,5 clo. Moreno, Noguchi e Labaki (2007) propuseram um gráfico tridimensional para análise de conforto em clima subtropical de altitude baseado no cruzamento de parâmetros ambientais - temperatura do ar, umidade relativa do ar e velocidade do vento $-\mathrm{e}$ entrevistas com usuários. Goyette-Pernot e Compagnon (2008) propuseram um método rápido de avaliação das sensações de conforto baseado nos resultados do projeto EU-RUROS ${ }^{1}$. Nesse estudo foram consideradas as relações empíricas dos parâmetros ambientais (temperatura do ar, velocidade do vento, temperatura radiante média) e resultados das entrevistas.

As características do entorno imediato interferem diretamente nos resultados de conforto térmico; sendo assim, o comportamento de indivíduos arbóreos no microclima varia conforme o tipo, porte, idade, período do ano e formas de disposição nos recintos urbanos (ABBUD, 2007; LABAKI; SANTOS, 1996; PEIXOTO; LABAKI; SANTOS, 1995). Abreu e Labaki (2008) verificaram, a partir do método de Moreno, Noguchi e Labaki (2007), que um indivíduo arbóreo isolado plantado em área gramada é capaz de proporcionar bem-estar ao usuário, ao longo do ano, em diferentes distâncias em relação ao tronco da árvore, mesmo não estando em área sombreada pela copa. A sensação de conforto varia principalmente pela densidade da copa de cada árvore, característica capaz de delimitar e restringir o espaço, a qual, dependendo da espécie, varia ao longo do ano, conforme a Figura 1.

A importância do presente estudo reside na identificação do índice mais aplicável na avaliação do raio de influência de indivíduos arbóreos de espécies decíduas e perenes no microclima urbano da cidade de Campinas, Brasil. Este trabalho dá continuidade ao estudo sobre a influência da vegetação no conforto térmico urbano e no ambiente construído de Labaki e Santos (1996) e Abreu e Labaki (2008).

\footnotetext{
${ }^{1}$ EU-RUROS (Europa Rediscovering the Urban Realm and Open Spaces) é um projeto de pesquisa desenvolvido por Nikolopoulou (2001) para avaliar as condições de conforto térmico, visual e acústico, microclima, morfologia urbana, entre outros, em várias cidades da Europa.
} 


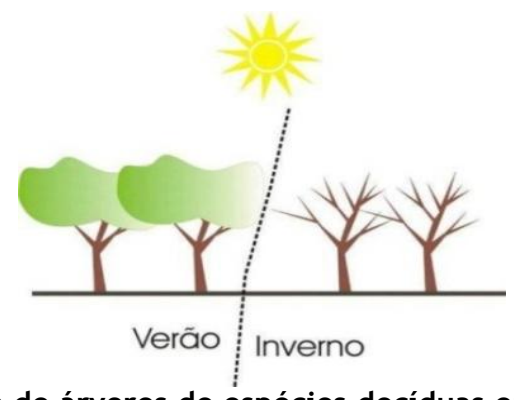

Figura 1 - Comportamento da copa de árvores de espécies decíduas em diferentes estações do ano

\begin{tabular}{|c|c|c|c|c|c|c|}
\hline Muito Frio & Frio & Levemente Frio & Confortável & $\begin{array}{c}\text { Levemente } \\
\text { Quente }\end{array}$ & Quente & Muito Quente \\
\hline-3 & -2 & -1 & 0 & 1 & 2 & 3 \\
\hline
\end{tabular}

Quadro 1 - Sensação térmica correspondente ao índice PMV

Este artigo tem como objetivo comparar os índices PMV (Voto Médio Estimado), de Fanger (1970), PET (Temperatura Fisiológica Equivalente), de Höppe (1999), e os resultados obtidos por meio dos gráficos gerados da Carta Bioclimática Tridimensional para clima Tropical de Altitude desenvolvida por Moreno, Noguchi e Labaki (2007), para a avaliação comparativa de conforto térmico proporcionado por indivíduos arbóreos isolados de diferentes espécies a diferentes distâncias. Objetiva também verificar a metodologia que melhor se aplica ao clima Tropical de Altitude, região de Campinas-SP, bem como as espécies arbóreas mais adequadas para a melhoria do microclima.

\section{Conforto em ambientes externos}

Vários índices são geralmente utilizados para a avaliação de conforto em espaços externos. Neste trabalho é analisada a aplicação dos índices PMV, PET e a Carta Bioclimática Tridimensional para clima Tropical de Altitude de Moreno, Noguchi e Labaki (2007).

\section{Voto Médio Estimado (PMV)}

O Voto Médio Estimado (PMV) de Fanger (1970) consiste em um método de predição da sensação térmica analítica de conforto, baseado no modelo de balanço térmico do corpo humano, função de parâmetros pessoais (atividades físicas e tipo de vestimenta) e de parâmetros ambientais (temperatura do ar, temperatura radiante média, umidade relativa e velocidade do ar). Com base no modelo de balanço térmico do corpo humano, foi desenvolvida a equação de conforto térmico. Posteriormente, a fim de conhecer o grau de desconforto experimentado pelas pessoas em ambientes com condições que não propiciam conforto, foi definido um critério para avaliar o grau de desconforto. Através da realização de ensaios com pessoas, relacionando as variáveis que influenciam no conforto térmico com uma escala de sensação térmica de -3 a +3 , foi proposto $o$ método do Voto Médio Estimado (PMV Predicted Mean Vote) (Quadro 1). A escala de PMV é simétrica, tendo o valor 0 (zero) como neutralidade térmica, e os valores de 1 a 3 como positivos, correspondendo às sensações de calor, ou negativos, correspondendo às sensações de frio.

\section{Temperatura Equivalente Fisiológica (PET)}

A Temperatura Equivalente Fisiológica (PET), desenvolvida por Höppe (1999), é um índice que define uma temperatura fisiológica equivalente em determinado local (ao ar livre ou em ambientes fechados) com uma temperatura do ar igual à de equilíbrio térmico do corpo humano (metabolismo de $80 \mathrm{~W}$ - atividade leve, adicionado ao metabolismo basal, resistência térmica do vestuário 0,9 clo). O modelo adota os seguintes parâmetros de referência:
(a) temperatura radiante média igual à temperatura do ar: $\mathrm{t}_{\mathrm{rm}}=\mathrm{t}_{\mathrm{ar}}$;
(b) velocidade do ar: $\mathrm{v}=0,1 \mathrm{~m} / \mathrm{s}$; e
(c) pressão parcial de vapor de água do ar: $\mathrm{pv}=$
$12 \mathrm{hPa}$ (correspondendo aproximadamente à umidade relativa do ar de $50 \%$ e a $\mathrm{t}_{\mathrm{ar}}=20{ }^{\circ} \mathrm{C}$ ). 


\begin{tabular}{|c|c|c|c|}
\hline PMV & PET $\left({ }^{\mathbf{0}} \mathbf{C}\right)$ & Sensação térmica & Nível de estresse térmico \\
\hline$-3,5$ & 4 & Muito frio & Frio extremo \\
\hline$-2,5$ & 8 & Frio & Frio forte \\
\hline$-1,5$ & 13 & Fresco & Moderadamente frio \\
\hline$-0,5$ & 18 & Levemente fresco & Ligeiramente Frio \\
\hline 0,5 & 23 & Levemente cálido & Ligeiramente quente \\
\hline 1,5 & 29 & Cálido & Moderadamente quente \\
\hline 2,5 & 35 & Quente & Calor forte \\
\hline 3,5 & 41 & Muito quente & Calor extremo \\
\hline
\end{tabular}

Quadro 2 - Comparação das taxas de Voto Médio Estimado (PMV) com a Temperatura Equivalente Fisiológica (PET) de Matzarakis, Mayer e Izionmon (1999)

\begin{tabular}{|c|c|c|}
\hline$\left.{ }^{\mathbf{0}} \mathbf{C}\right)$ & Sensação térmica & Pontuação \\
\hline$<4$ & Muito frio & -3 \\
\hline $4-12$ & Frio & -2 \\
\hline $12-18$ & Pouco frio & -1 \\
\hline $18-26$ & Neutra & 0 \\
\hline $26-31$ & Pouco calor & 1 \\
\hline $31-43$ & Calor & 2 \\
\hline$>43$ & Muito calor & 3 \\
\hline
\end{tabular}

Quadro 3 - Calibração do PET proposta por Monteiro e Alucci (2008)

A fim de comparar os resultados do Voto Médio Estimado (PMV) com o de Temperatura Equivalente Fisiológica (PET), Matzarakis, Mayer e Izionmon (1999) elaboraram o Quadro 2, estipulando diferentes níveis para as sensações humanas e estresse térmico dos seres humanos (produção interna de calor: $80 \mathrm{~W}$, resistência térmica do vestuário: 0,9 clo). O Quadro 2 foi elaborado com base na realidade europeia.

O Quadro 3 apresenta a calibração do índice PET para a realidade brasileira, proposta por Monteiro e Alucci (2008).

\section{Carta Bioclimática Tridimensional para Clima Tropical de Altitude}

O método de Moreno, Noguchi e Labaki (2007) consiste em uma Carta Bioclimática Tridimensional criada a partir do cruzamento de três variáveis ambientais - temperatura do ar, umidade relativa do ar e velocidade do vento -, em que foram definidos os intervalos considerados como confortáveis baseando-se na respostas de 108 pessoas em um bairro com características locais.

A Carta Bioclimática Tridimensional para Clima Tropical de Altitude (Figura 2) considera valores entre 1 e -1 correspondentes à sensação térmica, delimitando a zona de conforto com a gradação de
Confortável (C), Aceitável Conforto (AC), Tolerável Conforto (TC) e Desconfortável (D). A área classificada como confortável no gráfico está representada pela cor amarela, a aceitável conforto pela cor marrom, e a tolerável conforto pela cor cinza.

\section{Métodos de coleta de dados}

\section{Clima de Campinas}

Campinas está localizada a $22^{\circ} 48^{\prime} 57^{\prime}$ 'S, $47^{\circ} 03^{\prime} 33^{\prime \prime} \mathrm{W}$ e com altitude de $640 \mathrm{~m}$. O clima da cidade é classificado como Tropical de Altitude, sendo a média anual da temperatura do ar de 22,3 ${ }^{\circ} \mathrm{C}$, índice pluviométrico anual de $1.411 \mathrm{~mm}$, com a predominância de chuvas nos meses de novembro a março, e períodos de estiagem de 30 a 60 dias nos meses de julho e agosto. O período de verão, quando as temperaturas máximas variam entre $28,5^{\circ} \mathrm{C}$ e $30,5^{\circ} \mathrm{C}$, e as temperaturas mínimas variam entre $18,1^{\circ} \mathrm{C}$ e $19,9^{\circ} \mathrm{C}$, corresponde aos meses de novembro, dezembro, janeiro, fevereiro e março. O período de inverno, com temperaturas máximas variando entre $24,8{ }^{\circ} \mathrm{C}$ e $29,1{ }^{\circ} \mathrm{C}$ e as temperaturas mínimas entre $11,3{ }^{\circ} \mathrm{C}$ e $13,8{ }^{\circ} \mathrm{C}$, corresponde aos meses de junho, julho e agosto. Como o município tem um verão mais longo que o inverno, então existe uma predominância da estação quente (LAMOTTA; LABAKI, 2009). 

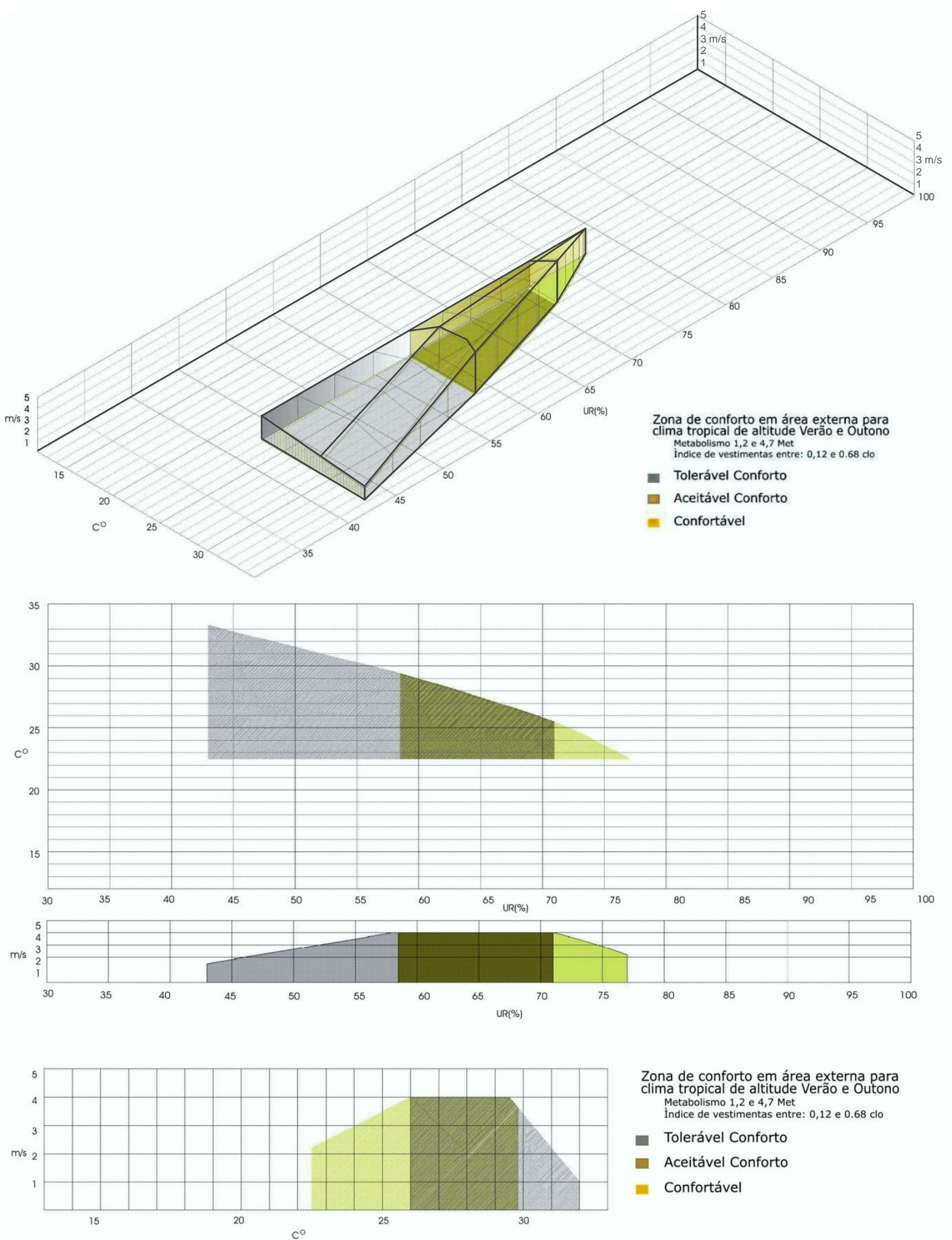

Zona de conforto em área externa para clima tropical de altitude Verão e Outono Metabolismo 1,2 e 4,7 Met
Indice de vestimentas entre: 0,12 e 0.68 clo

Tolerável Conforto

Aceitável Conforto

- Confortável

Figura 2 - Carta Bioclimática Tridimensional para Clima Tropical de Altitude 


\section{Seleção das escalas}

As escalas adotadas nesta pesquisa foram microclimática e instantânea, que permitem avaliar as condições de tempo e sua influência no entorno imediato em dias com poucas nuvens no céu (BUENO, 1998; BUENO-BARTHOLOMEI, 2003). A escala microclimática avalia o grau de influencia in loco de diferentes indivíduos arbóreos, sob um determinado tipo de solo, na atenuação da radiação solar e da variação da temperatura do ar e da umidade relativa do ar (PEREIRA; ANGELOCCI; SENTELHAS, 2002).

\section{Seleção dos locais de medição e dos indivíduos arbóreos das espécies selecionadas}

A escolha das espécies arbóreas baseou-se no guia de recomendação para arborização urbana da cidade de Campinas (PREFEITURA..., 2007) e naqueles indivíduos comumente disponíveis na região. Os indivíduos arbóreos selecionados foram encontrados em idade adulta e seguindo as características morfológicas da espécie definidas por Lorenzi (2002, 2003). Os indivíduos selecionados estão dispostos em uma área livre de interferência de elementos externos, tais como outras árvores e edificações, e situados em locais onde a topografia é pouco acidentada, livre de superfícies pavimentadas. Todos se encontram no campus da Universidade Estadual de Campinas (Figura 3).

Os indivíduos arbóreos selecionados são das espécies Tabebuia chrysotricha (Mart. ex DC.) Standl. (ipê-amarelo), Syzygium cumini L. (jambolão) e Mangifera indica L. (mangueira) (Figura 4). Suas características são apresentadas no Quadro 4.

Legenda:

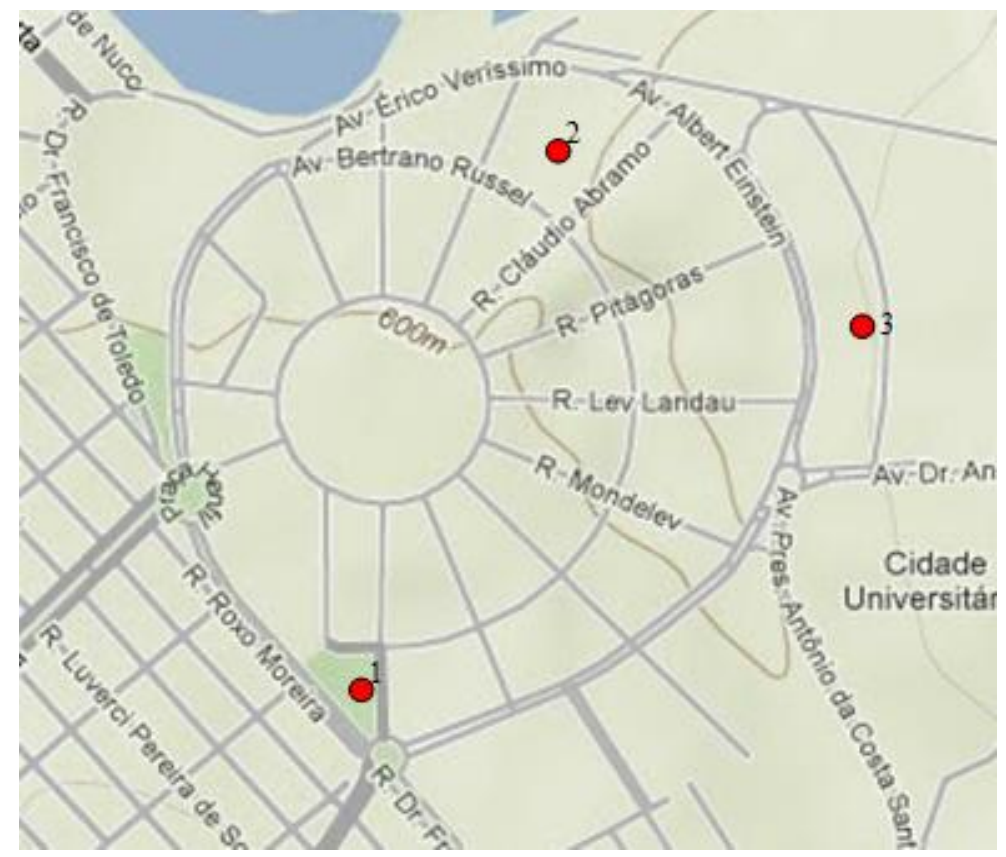

1- Syzygium cumini L. (jambolão);

2- Mangifera indica L. (mangueira);

3- Tabebuia chrysotricha (Mart. ex DC.) Standl. (ipê-amarelo).

Figura 3 - Localização das espécies no campus da Unicamp 


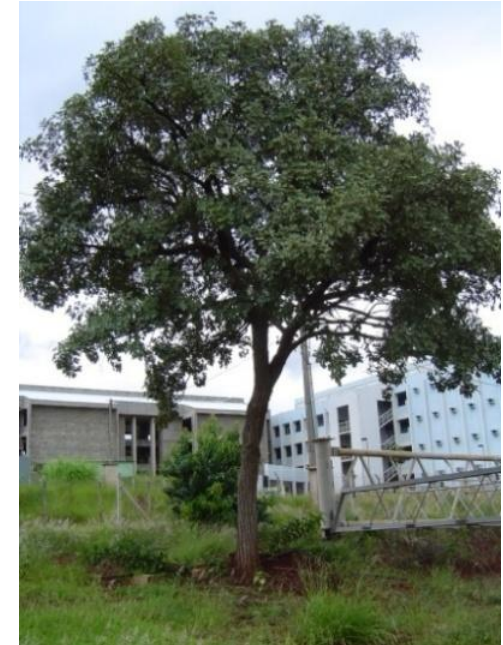

Ipê-amarelo - isolada com folhas (Tabebuia chrysotricha)

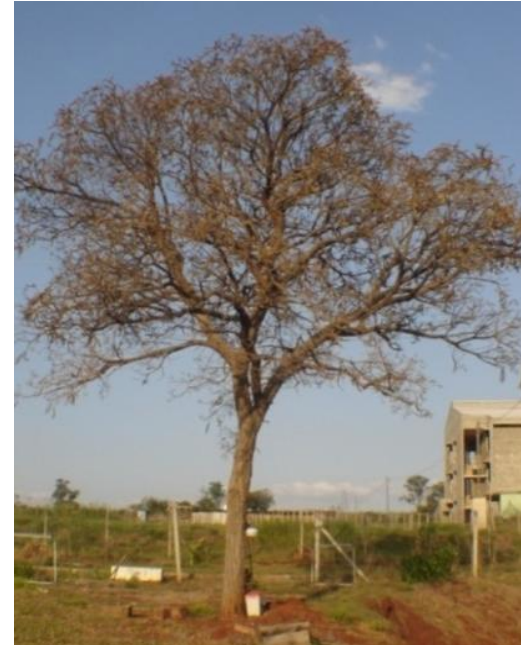

Ipê-amarelo - isolada sem folhas e flores (Tabebuia chrysotricha)

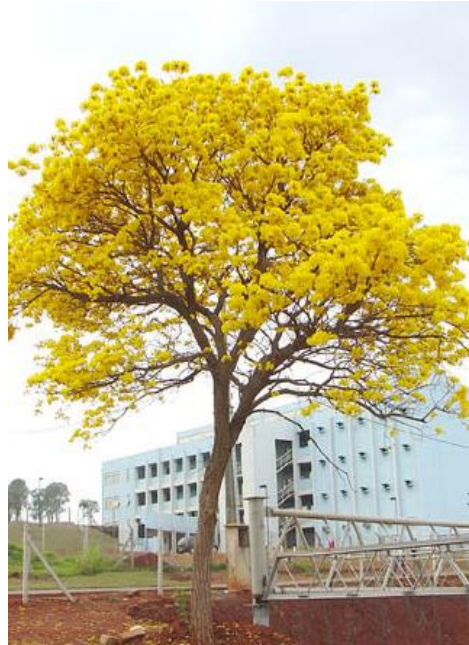

Ipê-amarelo - isolada com flores

(Tabebuia chrysotricha)

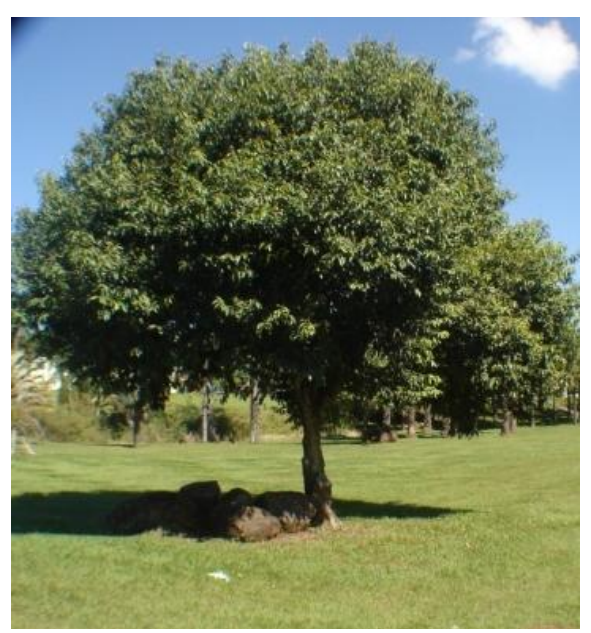

Jambolão (Syzygium cumini)

Figura 4 - Espécies analisadas isoladas

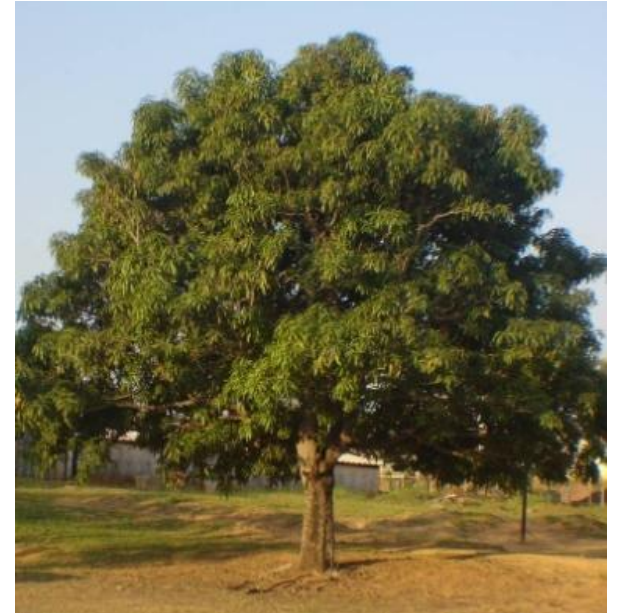

Mangueira (Mangifera indica)

\begin{tabular}{|c|c|c|}
\hline $\begin{array}{l}\text { Tabebuia chrysotricha (Mart. ex } \\
\text { DC.) Standl. - Ipê-amarelo }\end{array}$ & Syzygium cumini L. - Ja & Mangifera indica L. - M \\
\hline 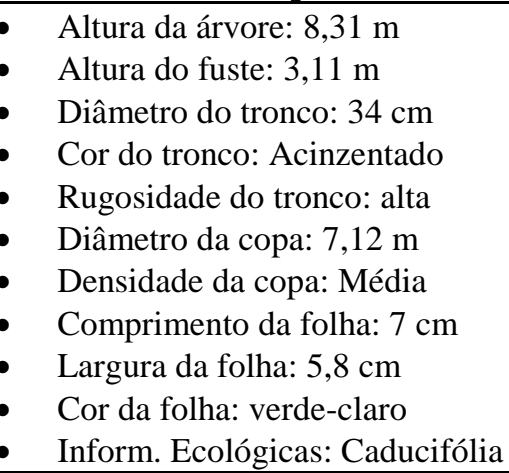 & $\begin{array}{ll}\text { - } & \text { Altura da árvore: } 8 \mathrm{~m} \\
\text { - } & \text { Altura do fuste: } 1,75 \mathrm{~m} \\
\text { - } & \text { Cor do tronco: Marrom-claro } \\
\text { - } & \text { Dugosidade do tronco: Média } \\
\text { - } & \text { Densidade da copa: Alta } \\
\text { - } & \text { Comprimento da Folha: } 15 \mathrm{~cm} \\
\text { - } & \text { Largura da folha: } 6,0 \mathrm{~cm} \\
\text { - } & \text { Inform. ecológicas: Perenifólia }\end{array}$ & $\begin{array}{ll}\text { - } & \text { Altura da árvore: } 8,48 \mathrm{~m} \\
\text { - } & \text { Altura do fuste: } 1,70 \mathrm{~m} \\
\text { - } & \text { Cor do tronco: Marrom-claro } \\
\text { - } & \text { Diâmetro da copa: } 9,52 \mathrm{~m} \\
\text { - } & \text { Densidade da copa: Alta } \\
\text { - } & \text { Largura da folha: } 5,5 \mathrm{~cm} \\
\text { - } & \text { Cor da folha: Verde-escuro } \\
\text { - } & \text { Inform. ecológicas: Perenifólia }\end{array}$ \\
\hline
\end{tabular}

Quadro 4 - Características dos indivíduos arbóreos analisados 


\section{Levantamento dos parâmetros ambientais}

Os equipamentos foram fixados a um tripé na altura de $1,50 \mathrm{~m}$, conforme a Figura 5, um registrador de temperatura e umidade relativa do ar, modelo Testo 175 , protegido da radiação; um sensor de temperatura, modelo Testo 175-T2; outro sensor de temperatura, modelo Testo 0613 1711 adaptado ao globo; um anemômetro/termômetro digital Testo 445 com sensor 0635-1549 acoplado a um tripé (Figura 6). Os dados foram registrados de $10 \mathrm{em} 10 \mathrm{~min}$, por um período de $12 \mathrm{~h}$, das $6 \mathrm{~h}$ às $18 \mathrm{~h}$

Os dados coletados foram: temperatura do ar, temperatura de globo, umidade relativa do ar, em 4 posições fixas - à sombra, a 2,5 m, e ao sol, a 10 m, a $25 \mathrm{~m}$ e a $50 \mathrm{~m}$ do tronco da árvore (Figura 7) -, e velocidade do vento, em 1 posição fixa - a 15 $\mathrm{m}$ do tronco da árvore.

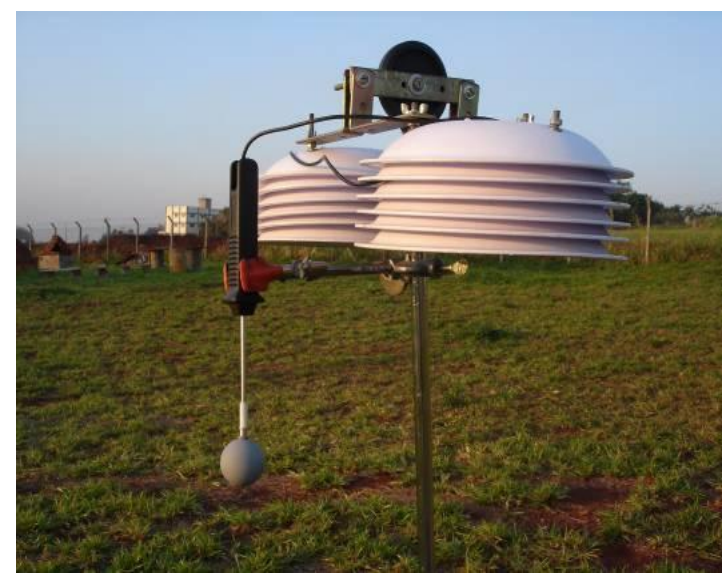

Figura 5 - Registradores acoplados ao tripé

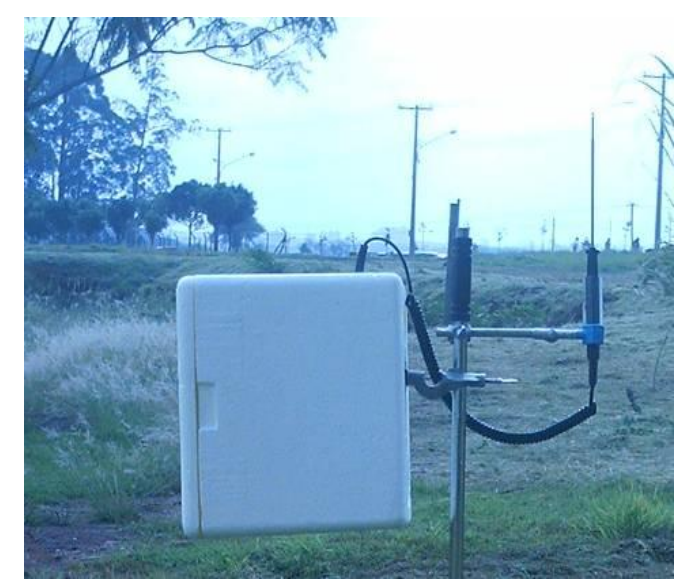

Figura 6 - Anemômetro acoplado ao tripé

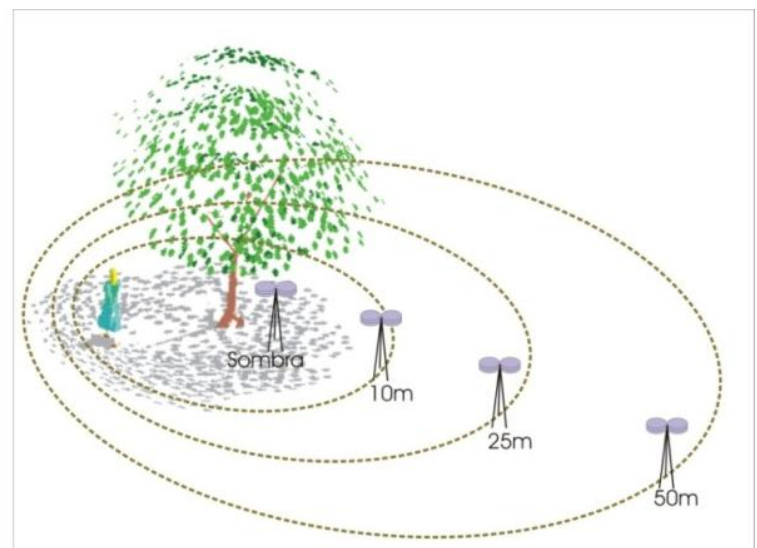

Figura 7 - Posicionamento dos tripés com registradores

110 Abreu, L. V. de; Labaki, L. C. 
Os registradores acoplados ao tripé foram posicionados para o norte, evitando sombreamento da própria árvore estudada ao longo do dia, conforme se observa pela localização dos equipamentos no indivíduo arbóreo da espécie Tabebuia chrysotricha (Mart. ex DC.) Standl. (ipêamarelo) (Figura 8). Durante a localização dos pontos de medição, considerou-se para análise um quadrante de estudo com cobertura vegetal, grama ou capim, com altura máxima de $15 \mathrm{~cm}$ e livre de obstáculos. Para este estudo, adotou-se apenas um ponto de coleta de velocidade do ar, por ser esse parâmetro necessário para o cálculo de conforto térmico na escala microclimática. Medições realizadas em diferentes pontos mostraram que a variação da velocidade do vento depende das condições climáticas, e não da posição em relação à árvore. Salienta-se que o objetivo deste estudo é a avaliação da sensação de conforto, e não do comportamento do vento em torno do corpo da árvore.

As medições foram realizadas em duas estações, inverno e verão, dos anos de 2007 a 2010. O período de medição durante cada estação foi de três dias típicos - dias com predominância de sol e ausência de chuvas, de acordo com metodologia de
Katzschner, Bosch e Rvttgen (2002), BuenoBartholomei (2003) e Pezzuto e Labaki (2007). Mais detalhes sobre os dados coletados encontramse em Abreu (2008).

\section{Tratamento dos dados}

Os dados coletados foram manipulados por três formas diferentes: Voto Médio Estimado (PMV), de Fanger (1970), Temperatura Equivalente Fisiológica (PET), de Höppe (1999), e Carta Bioclimática Tridimensional para Clima Tropical de Altitude, de Moreno, Noguchi e Labaki (2007). Para simular o conforto térmico de um indivíduo, considerou-se um usuário com metabolismo igual a $80 \mathrm{~W}$ e resistência térmica da vestimenta igual a 0,9 clo para as duas estações, inverno e verão. Salienta-se que neste estudo a resistência térmica não foi alterada devido às características do clima da região, que, apesar da amplitude térmica ao longo do ano, durante as duas estações, não apresenta situações extremas, que justifiquem a alteração da vestimenta, principalmente nos horários estudados. Os dados de temperatura do ar e de globo, umidade e velocidade do ar utilizados no cálculo encontram-se em Abreu (2008).

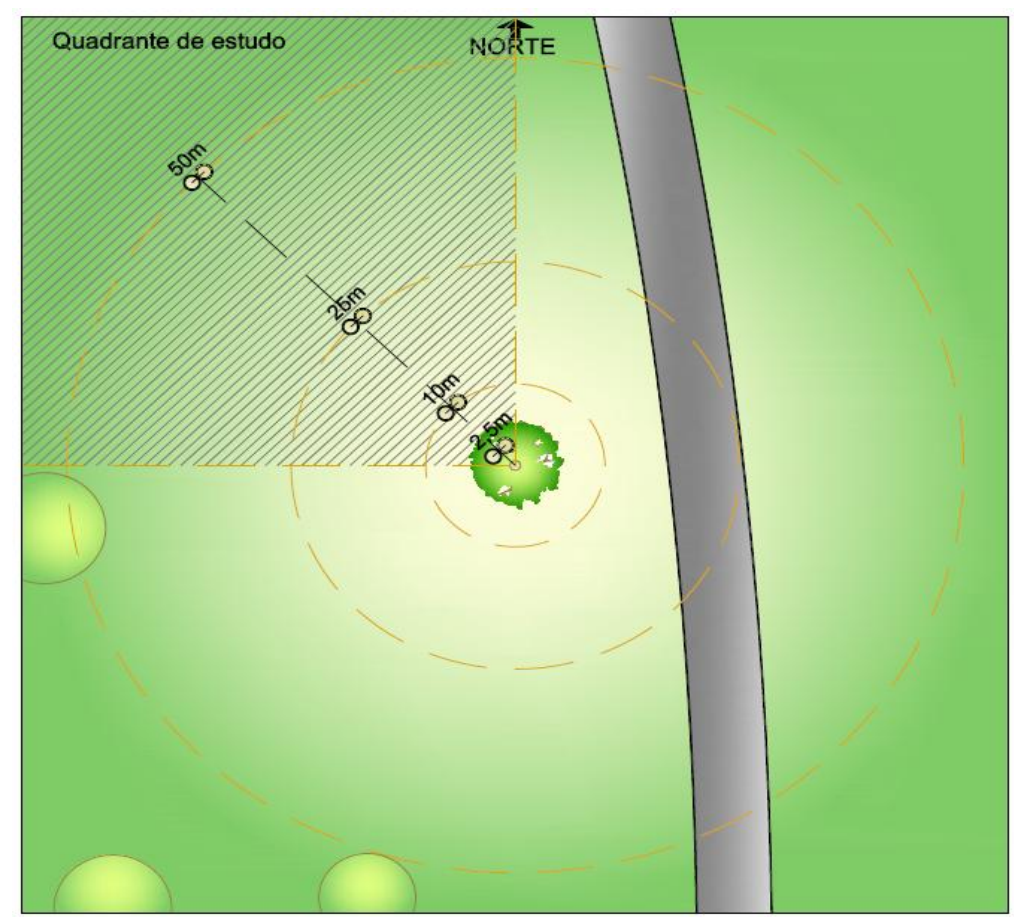

Figura 8 - Posicionamento dos registradores na espécie ipê-amarelo, Tabebuia Chrysotricha 


\begin{tabular}{c|c|c|c|c|c}
\hline \multirow{2}{*}{ PMV } & \multirow{2}{*}{ PET $\left({ }^{\mathbf{0}} \mathbf{C}\right)$} & \multicolumn{2}{|c|}{ Carta Bioclimática Tridimensional } & \multirow{2}{*}{ Sensação térmica } \\
\cline { 3 - 5 } & 15 & Ta $\left({ }^{\mathbf{0}} \mathbf{C}\right)$ & $\mathbf{U r}(\boldsymbol{\%})$ & $\mathbf{v}(\mathbf{m} / \mathbf{s})$ & \multirow{2}{*}{ Pouco frio } \\
\hline-1 & --- & --- & -- & Levemente fresco \\
\hline$-0,5$ & 18 & --- & --- & -- & Confortável \\
\hline 0 & 20,5 & 25 a 26 & 77 a 71 & 0 a 2,33 & Levemente cálido \\
\hline 0,5 & 23 & 26 a 28,4 & 70 a 58,5 & 2,34 a 3,69 & Pouco calor \\
\hline 1 & 28,5 & 28,5 a 33,5 & 58,6 a 43 & 2,34 a 3,69 & . \\
\hline
\end{tabular}

Tabela 1 - Quadro de equivalência dos índices PMV, PET e Carta Bioclimática Tridimensional

Para calcular o PET e o PMV simultaneamente, utilizou-se o software Rayman 1.2, desenvolvido por Matzarakis, Rutz e Mayer (2006). Nesse programa são inseridos dados do dia (data e hora), dados geográficos (latitude, longitude, altitude), dados meteorológicos (temperatura do ar, velocidade do vento, umidade relativa do ar, bem como os fluxos de radiação de ondas longa e curta), dados termofisiológicos (atividade e roupas) e dados específicos de cada indivíduo (altura, peso, idade e sexo), assim como informações adicionais sobre os obstáculos, como as dimensões das árvores (espécies decíduas ou coníferas). O software permite também a inserção de foto com lentes olho de peixe (fish-eye) do local de medição. Os dados de saída final do programa são os índices PMV, PET ou $\mathrm{SET}^{2,}$ a partir do cálculo da temperatura radiante média.

Para o cálculo de conforto pela Carta Bioclimática Tridimensional para clima Tropical de Altitude, de Moreno, Noguchi e Labaki (2007), os dados climáticos de cada hora foram inseridos no sistema cartesiano do software AutoCad 2007, onde a temperatura do ar refere-se ao eixo " $X$ ", a umidade relativa do ar, "Y", e a velocidade do vento, " $Z$ ". O ponto que estiver dentro do volume da área de conforto é considerado como confortável. A imagem gerada foi tratada pelo programa CorelDraw 11.

A fim de comparar os resultados obtidos de hora em hora por índice de conforto, foi desenvolvida a Tabela 1, equiparando os índices PMV, PET e Carta Bioclimática Tridimensional dentro do intervalo pouco frio a pouco calor (-1 a 1) das sensações térmicas. Os valores considerados para o índice PET foram aqueles calibrados por Monteiro e Alucci (2008). Os valores considerados para a Carta Bioclimática Tridimensional foram os resultados obtidos por Moreno, Noguchi e Labaki (2007) ao longo do ano.
Os resultados obtidos a cada hora, que se encontraram no intervalo pouco frio a pouco calor (-1 a 1) das sensações térmicas do quadro de equivalência (Tabela 2 ), foram considerados como uma Unidade de Hora Confortável (UHC). Com o somatório das unidades de UHC obtidas a cada hora, compararam-se os índices em diferentes estações e espécies arbóreas.

\section{Análise dos resultados}

Para analisar os resultados dos índices PET, PMV e Carta Bioclimática Tridimensional para clima Tropical de Altitude, foi construída uma tabela contendo as horas analisadas do dia, os valores correspondentes para as sensações térmicas segundo o quadro de equivalência dos índices (Tabela 1) e suas respectivas UCHs. A Tabela 2 apresenta os resultados para ipê-amarelo (Tabebuia chrysotricha) no inverno e exemplifica a forma como foi estabelecida a equivalência das sensações térmicas dos índices e a quantificação da UHC para cada hora.

A partir dos resultados de UHC em diferentes distâncias, criou-se um quadro-resumo comparativo para as espécies ipê-amarelo (Tabebuia chrysotricha), jambolão (Syzygium cumini) e mangueira (Mangifera indica) em duas estações (inverno e verão). A espécie decídua, ipêamarelo (Tabebuia chrysotricha), foi avaliada em duas situações (sem folhas e com flores) no inverno.

A Figura 9 apresenta os resultados para a espécie ipê-amarelo (Tabebuia chrysotricha) no inverno, situação com flores e sem folhas, e no verão, situação com folhas.

\footnotetext{
${ }^{2}$ SET (New Standard Effective Temperature) é a nova temperatura efetiva padrão proposta por Gagge, Fobelets e Bergulund (1986), baseada na combinação dos dados meteorológicos e nas condições de temperatura da pele e da fração coberta por suor do indivíduo.
} 


\begin{tabular}{|c|c|c|c|c|c|c|c|c|c|c|c|c|}
\hline \multicolumn{13}{|c|}{ Tabebuia chrysotricha (Ipê-amarelo) sem folhas - inverno } \\
\hline Lugar & \multicolumn{6}{|c|}{ Sombra } & \multicolumn{6}{|c|}{$10 \mathrm{~m}$} \\
\hline \multirow{2}{*}{ Hora } & \multicolumn{2}{|c|}{ PMV } & \multicolumn{2}{|c|}{ PET } & \multicolumn{2}{|c|}{ Carta } & \multicolumn{2}{|c|}{ PMV } & \multicolumn{2}{|c|}{ PET } & \multicolumn{2}{|c|}{ Carta } \\
\hline & Result. & UHC & Result. & UHC & Result. & UHC & Result. & UHC & Result. & UHC & Result. & UHC \\
\hline 06:00 & $-2,0$ & - & $-2,0$ & - & - & - & $-1,9$ & - & $-2,0$ & - & - & - \\
\hline 07:00 & $-2,2$ & - & $-2,0$ & - & - & - & $-2,1$ & - & $-2,0$ & - & - & - \\
\hline 08:00 & $-1,3$ & - & $-1,0$ & 1 & - & - & $-1,2$ & - & $-1,3$ & - & - & - \\
\hline 09:00 & $-0,6$ & 1 & $-1,0$ & 1 & - & - & $-0,6$ & 1 & $-1,0$ & 1 & - & - \\
\hline $10: 00$ & 0,1 & 1 & $-0,5$ & 1 & - & - & 0,1 & 1 & $-0,5$ & 1 & - & - \\
\hline 11:00 & 0,4 & 1 & $-0,5$ & 1 & 1,0 & 1 & 0,4 & 1 & $-0,5$ & 1 & - & - \\
\hline $12: 00$ & 0,9 & 1 & $-0,5$ & 1 & 1,0 & 1 & 0,9 & 1 & 0,0 & 1 & - & - \\
\hline $13: 00$ & 1,3 & - & 1,0 & 1 & - & - & 1,3 & - & 0,5 & 1 & - & - \\
\hline $14: 00$ & 1,4 & - & 1,0 & 1 & - & - & 1,4 & - & 1,0 & 1 & - & - \\
\hline $15: 00$ & 1,6 & - & 1,0 & 1 & - & - & 1,6 & - & 1,5 & - & - & - \\
\hline $16: 00$ & 1,4 & - & 1,0 & 1 & - & - & 1,4 & - & 1,0 & 1 & - & - \\
\hline $17: 00$ & 1,2 & - & 1,0 & 1 & - & - & 1,2 & - & 1,0 & 1 & - & - \\
\hline 18:00 & 0,2 & 1 & 0,0 & 1 & 1,0 & 1 & 0,2 & 1 & $-0,5$ & 1 & 1,0 & 1 \\
\hline Lugar & \multicolumn{6}{|c|}{$25 \mathrm{~m}$} & \multicolumn{6}{|c|}{$50 \mathrm{~m}$} \\
\hline \multirow{2}{*}{ Hora } & \multicolumn{2}{|c|}{ PMV } & \multicolumn{2}{|c|}{ PET } & \multicolumn{2}{|c|}{ Carta } & \multicolumn{2}{|c|}{ PMV } & \multicolumn{2}{|c|}{ PET } & \multicolumn{2}{|c|}{ Carta } \\
\hline & Result. & UHC & Result. & UHC & Result. & UHC & Result. & UHC & Result. & UHC & Result. & UHC \\
\hline 06:00 & $-1,9$ & - & $-2,0$ & - & - & - & $-1,9$ & - & $-2,0$ & - & - & - \\
\hline 07:00 & $-2,1$ & - & $-2,0$ & - & - & - & $-2,1$ & - & $-2,0$ & - & - & - \\
\hline 08:00 & $-1,2$ & - & $-1,5$ & - & - & - & $-1,2$ & - & $-1,5$ & - & - & - \\
\hline 09:00 & $-0,7$ & 1 & $-1,0$ & 1 & - & - & $-0,5$ & 1 & $-1,0$ & 1 & - & - \\
\hline $10: 00$ & 0,0 & 1 & $-0,5$ & 1 & - & - & 0,1 & 1 & $-0,5$ & 1 & - & - \\
\hline 11:00 & 0,4 & 1 & $-0,5$ & 1 & - & - & 0,4 & 1 & $-0,5$ & 1 & - & - \\
\hline $12: 00$ & 0,6 & 1 & 0,0 & 1 & 1,0 & 1 & 0,8 & 1 & 0,0 & 1 & 1,0 & 1 \\
\hline 13:00 & 1,0 & 1 & 0,5 & 1 & - & - & 1,3 & - & 0,5 & 1 & - & - \\
\hline 14:00 & 1,3 & - & 1,5 & - & - & - & 1,5 & - & 1,5 & - & - & - \\
\hline $15: 00$ & 1,4 & - & 1,0 & 1 & - & - & 1,6 & - & 1,0 & 1 & - & - \\
\hline $16: 00$ & 1,2 & - & 1,0 & 1 & - & - & 1,5 & - & 0,5 & 1 & - & - \\
\hline $17: 00$ & 1,2 & - & 0,5 & 1 & - & - & 1,2 & - & 0,5 & 1 & - & - \\
\hline $18: 00$ & 0,1 & 1 & $-0,5$ & 1 & 1,0 & 1 & 0,2 & 1 & $-0,5$ & 1 & 1,0 & 1 \\
\hline
\end{tabular}

Tabela 2 - Resultado dos índices de conforto para Tabebuia chrysotricha (ipê-amarelo) sem folhas inverno

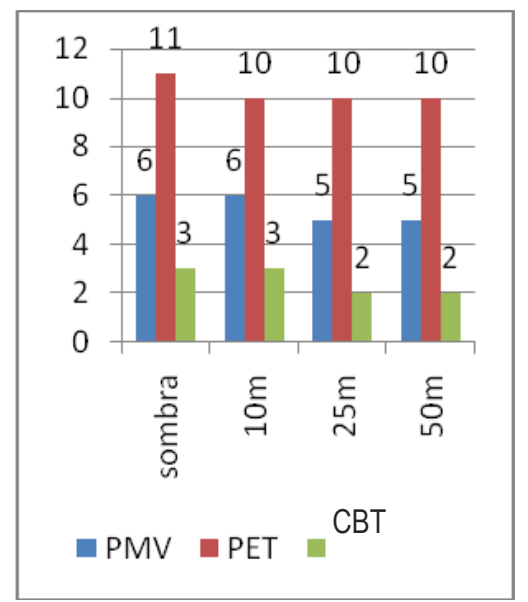

Ipê-amarelo sem folhas

(Tabebuia chrysotricha) - inverno

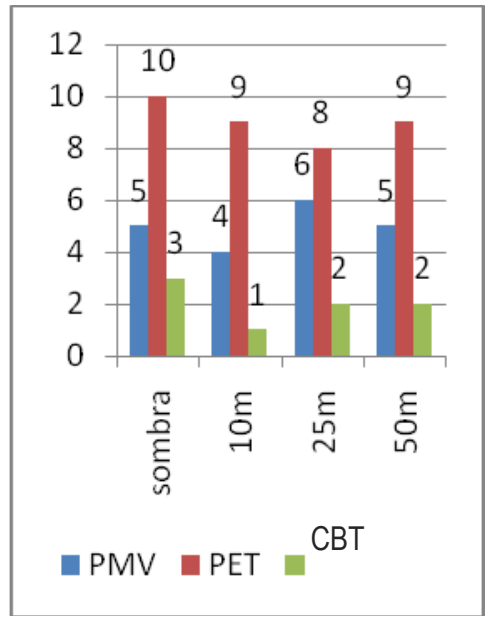

Ipê-amarelo com flores

(Tabebuia chrysotricha) - inverno

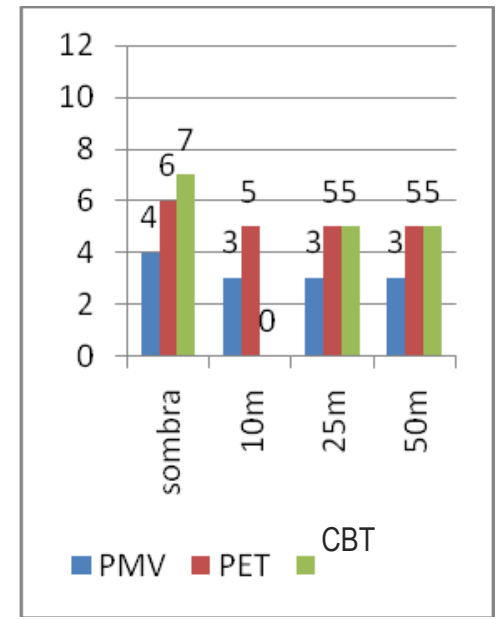

Ipê-amarelo com folhas

(Tabebuia chrysotricha) - verão

Figura 9 - Comparação dos resultados de UHC da espécie decídua ipê-amarelo (Tabebuia chrysotricha) com folhas no inverno e verão 
Para o ipê-amarelo (Tabebuia chrysotricha) nas situações sem folhas e com flores, os intervalos de valores obtidos pelos índices PMV, PET e Carta Bioclimática Tridimensional mostram uma variação máxima de 8 UHCs. No inverno, o índice PET encontrou mais horas de conforto do que o PMV e a Carta Bioclimática Tridimensional. Por exemplo, na situação sem folhas a $25 \mathrm{~m}$ e a $50 \mathrm{~m}$, o resultado do PET é de 10 UHCs, enquanto para o PMV e a Carta Bioclimática Tridimensional é, respectivamente, 5 e 2 . Na situação com folhas, os resultados obtidos pelos três índices possuem intervalos menores. Para o índice PET e a Carta Bioclimática Tridimensional a $25 \mathrm{~m}$ e $50 \mathrm{~m}$, os valores foram idênticos. O PMV, na situação com folhas, mostrou valores menores de UHC do que nas situações sem folhas e com flores. Na situação com folhas, os três indicadores trazem boas respostas para conforto térmico em ambientes externo.

A Figura 10 apresenta os resultados para a espécie jambolão (Syzygium cumini) no inverno e no verão. Observa-se que essa espécie apresentou uma diferença de 10 UHCs entre os valores obtidos pelos índices PMV, PET e Carta Bioclimática Tridimensional à sombra no inverno. No verão, a diferença máxima entre os resultados dos índices foi de 5 UHCs. No inverno, o PET mostrou um maior número de UHCs que o PMV e a Carta Bioclimática Tridimensional. No verão, os intervalos entre os resultados obtidos pelos três índices foram menores do que aqueles obtidos no inverno.

A Figura 11 apresenta os resultados para a espécie mangueira (Mangifera indica) no inverno e no verão. Os resultados obtidos pelos índices PMV, PET e Carta Bioclimática Tridimensional para essa espécie apresentam uma diferença máxima de 6 UHCs no inverno e de 5 UHCs no verão. No inverno, os índices PMV e PET mostram um valor de UHC à sombra, 9 UHCs, maior do que nas outras distâncias. Já no verão, os três índices apresentam 8 e 10 UHCs à sombra, porém os índices PET e Carta Bioclimática Tridimensional mantêm os mesmos resultados nas outras distâncias.

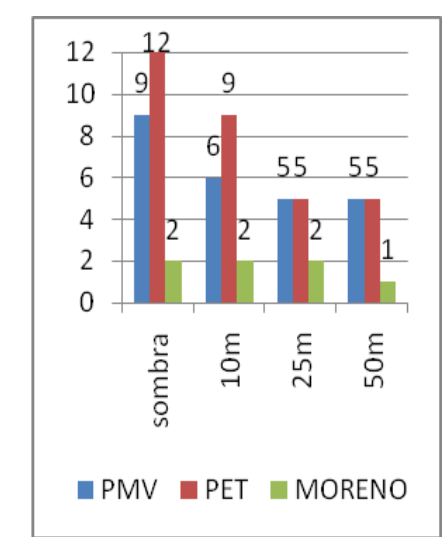

Jambolão (Syzygium cumini) -inverno

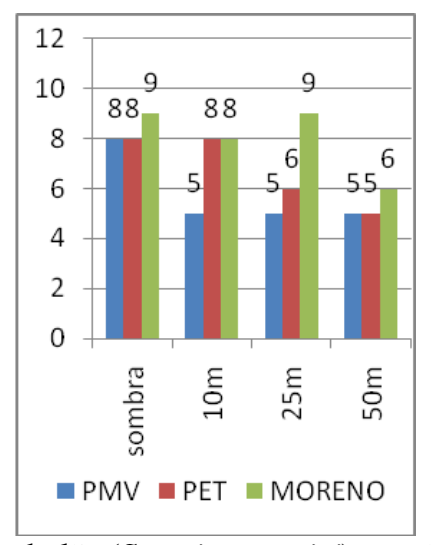

Jambolão (Syzygium cumini) - verão

Figura 10 - Comparação dos resultados UHC da espécie jambolão (Syzygium cumini) no inverno e no verão

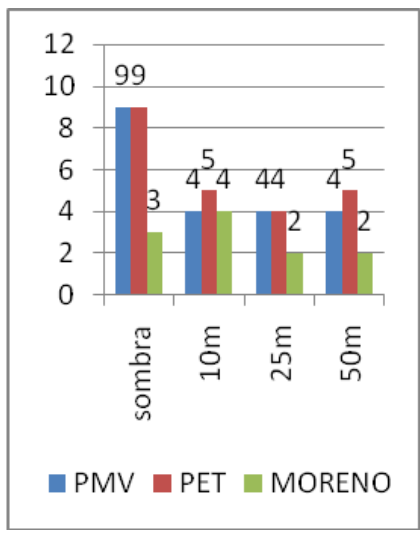

Mangueira (Mangifera indica) - inverno

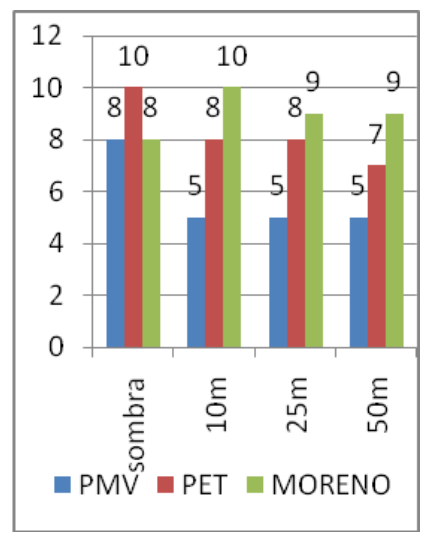

Mangueira (Mangifera indica) - verão

Figura 11 - Comparação dos resultados UHC da espécie mangueira (Mangifera indica) no inverno e no verão 
Para todos os índices, os resultados mostram que as três espécies analisadas, ipê-amarelo (Tabebuia chrysotricha), jambolão (Syzygium cumini) e mangueira (Mangifera indica), influenciam nas sensações de conforto no entorno imediato durante o período de verão. Porém, a espécie decídua, ipêamarelo (Tabebuia chrysotricha), também proporciona maior conforto térmico no entorno imediato durante o inverno. Já para as espécies perenes, jambolão (Syzygium cumini) e mangueira (Mangifera indica), as sensações de conforto se restringem à sombra.

Os resultados dos índices PMV, PET e Carta Bioclimática Tridimensional no verão, para as três espécies, apresentaram menores intervalos de conforto do que os de inverno. Esses resultados sugerem que, no período de verão, os índices apresentam valores mais próximos da real sensação térmica dos indivíduos. Os dados de temperatura do ar e umidade relativa do ar são os parâmetros ambientais que mais interferem nos resultados de conforto para os três índices.

\section{Conclusões}

Em relação à influência das árvores no microclima urbano, pode-se afirmar que todas as espécies arbóreas avaliadas foram capazes de alterar a sensação de conforto térmico no entorno imediato. Espécies decíduas, como ipê-amarelo (Tabebuia chrysotricha), proporcionam boas condições de conforto em diferentes distâncias durante o ano. Já as espécies perenes, como jambolão (Syzygium cumini) e mangueira (Mangifera indica), têm maior influência na sensação térmica no entorno imediato no período de verão do que no inverno, quando condições mais confortáveis são encontradas à sombra da copa da árvore durante as duas estações. Esse fenômeno é explicado pela característica termorreguladora das árvores, que mantém a temperatura e a umidade relativa do ar a seu redor em uma faixa ideal para seu sustento. As folhas das árvores possuem células denominadas estômatos, responsáveis pela termorregulação, abrem-se quando encontram temperatura $\mathrm{e}$ umidade relativa do ar ideais e fecham-se quando começam a perder água (PEREIRA; GREEN; VILLA NOVA, 2006). Sendo assim, os indivíduos arbóreos influenciam principalmente na temperatura do ar e umidade relativa do ar ao longo do ano, numa escala microclimática.

$\mathrm{O}$ índice PMV, mais recomendado para ambientes internos, e o PET, sensível à umidade, são importantes ferramentas para a qualificação de conforto térmico em espaços abertos. Salienta-se que os índices adaptados ao clima local e aos costumes dos usuários mostram respostas em maior concordância com a real sensação térmica dos indivíduos, principalmente em estudos nos quais não há possibilidade de pesquisa com usuários.

A utilização de modelos matemáticos, como os índices PMV e PET, na avaliação de conforto térmico em ambiente externo auxilia na definição de intervalos das variáveis climáticas que causam conforto (temperatura do ar e de globo, umidade relativa do ar e velocidade do ar). Esses intervalos referentes à sensação térmica dos indivíduos permitem a avaliação rápida em uma escala microclimática de locais com as mesmas características, bem como definir uma Carta Bioclimática Tridimensional, como a de Moreno, Noguchi e Labaki (2007).

A definição de cartas bioclimáticas para determinado local, fundamentada na opinião das pessoas, conforme o método de Moreno, Noguchi e Labaki (2007), é uma ferramenta importante para o estudo de conforto em espaços externos. Após a construção da carta bioclimática, é possível fazer uma rápida avaliação de conforto térmico de um ambiente externo, sem necessidade de entrevistas com os usuários para sua validação. A principal limitação desse método é a dificuldade do tratamento dos dados coletados em campo para a definição dos intervalos das variáveis climáticas que causam conforto e, consequentemente, o desenvolvimento da Carta Bioclimática Tridimensional.

É importante a realização de tais estudos para se identificar a metodologia de análise de conforto térmico que melhor responda aos objetivos da pesquisa. Como continuidade deste trabalho, sugere-se a elaboração de cartas bioclimáticas de conforto térmico para outros climas segundo o método de Moreno, Noguchi e Labaki (2007) e a calibração dos modelos PET e PMV para o clima local.

O conhecimento do comportamento das espécies em relação ao conforto térmico no microclima é importante para os planejadores e pesquisadores do ambiente construído, para que seja incorporado no planejamento ou intervenções dos espaços abertos, aproveitando-se com inteligência os benefícios dos indivíduos arbóreos, visando à melhoria da qualidade de vida das pessoas.

\section{Referências}

ABBUD, B. Criando Paisagens: guia de trabalho em arquitetura paisagística. 3. ed. São Paulo:

Senac, 2007. 
ABREU, L. V.; LABAKI, L. C. Avaliação da Termo-Regulação em Diferentes Espécies Arbóreas. In: ENCONTRO NACIONAL DE TECNOLOGIA DO AMBIENTE CONSTRUIIDO, 12., Fortaleza, 2008. Anais... Fortaleza: Antac, 2008. 1 CD-ROM.

\section{ABREU, L. V. Estudo do Raio de Influência da Vegetação no Microclima por Diferentes Espécies Arbóreas. 2008. 154 f. Dissertação (Mestrado em Engenharia Civil) - Faculdade de Engenharia Civil, Arquitetura e Urbanismo, Universidade Estadual de Campinas, Campinas, 2008.}

AHMED, K. S. Comfort in Urban Spaces: defining the boundaries of outdoor thermal comfort for the tropical urban environments. Energy and Buildings, v. 35, n. 1, p. 103-110, 2003.

BUENO-BARTHOLOMEI, C. L. Influência da Vegetação no Conforto Térmico Urbano e no Ambiente Construído. 2003. 189 f. Tese (Doutorado em Engenharia Civil) - Faculdade de Engenharia Civil, Arquitetura e Urbanismo, Universidade Federal de Campinas, Campinas, 2003.

BUENO, C. L. Estudo da Atenuação da Radiação Solar Incidente por Diferentes Espécies Arbóreas. 1998. 177 f. Dissertação (Mestrado em Engenharia Civil) - Faculdade de Engenharia Civil, Universidade Federal de Campinas, Campinas, 1998.

FANGER, P. Thermal Comfort. New York: McGraw-Hill, 1970.

GAGGE, A.; FOBELETS, A. P., and BERGULUND, L, G. A Standard Predictive Index of Human Response to the Thermal Environment. ASHRAE Trans, v. 92, p. 709-731, 1986.

GOYETTE-PERNOT, J.; COMPAGNON, R. Outdoor Comfort in Open Spaces: proposal for a quick evaluation method. In: PASSIVE AND LOW ENERGY ARCHITECTURE, Dublin, 2008. Proceedings... Dublin: PLEA International, 2008. 1 CD-ROM.

GULYÁS, Á.; UNGER, J.; MATZARAKIS, A. Assessment of the Microclimatic and Thermal Comfort Conditions in a Complex Urban Environment: modeling and measurements. Building and Environment, v. 41, p. 1713-1722, 2006.
HÖPPE, P. The Physiological Equivalent Temperature: a universal index for the biometeorological assessment of the thermal environment. International Journal of Biometeorology, Dordrecht, v. 43, p. 71-75, 1999.

KATZSCHNER, L.; BOSCH, U.; RVTTGEN, M. Behavior of People in open Spaces Independency of Thermal Comfort Conditions. In: PASSIVE AND LOW ENERGY ARCHITECTURE, Toulouse, 2002. Proceedings... Toulouse: PLEA Internacional, 2002. p. 411-415.

LABAKI, L. C.; SANTOS, R. F. Conforto Térmico em Cidades: efeito da arborização no controle da radiação solar. Projeto FAPESP. Faculdade de Engenharia Civil, Unicamp, 1996.

LAMOTTA, M. G.; LABAKI, L. C. Dez Anos Depois: estudo do clima de Campinas. In: ENCONTRO NACIONAL DE E VI LATINO AMERICANO DE CONFORTO NO AMBIENTE CONSTRUÍDO, 10., Natal, 2009. Anais... Natal: Antac, 2009. 1 CD-ROM.

LORENZI, H. Árvores Brasileiras: manual de identificação e cultivo de plantas arbóreas nativas do Brasil. Nova Odessa, SP: Instituto Plantarum de Estudos da Flora, 2002. 368 p.

LORENZI, H. Árvores Exóticas no Brasil: madeireiras, ornamentais e aromáticas. Nova Odessa, SP: Instituto Plantarum de Estudos da Flora, 2003. 368 p.

MATZARAKIS, A.; MAYER, H.; IZIONMON, M. G. Applications of a Universal Thermal Iindex: physiological equivalent temperature.

International Journal of Biometeorology, v. 43, p. 76-84, 1999 .

MATZARAKIS, A.; RUTZ, F.; MAYER, H. Modelling the Thermal Bioclimate in Urban Areas with the RayMan Model. In: PASSIVE AND LOW ENERGY ARCHITECTURE, Geneva, 2006. Proceedings... Geneva: PLEA International, 2006. 1 CD-ROM.

MONTEIRO, L. M.; ALUCCI, M. P. Modelos Preditivos de Estresse Termo-Fisiológico: estudo empírico comparativo em ambientes externos. In: ENCONTRO NACIONAL DE TECNOLOGIA NO AMBIENTE CONSTRUÍDO, 12., Fortaleza, 2008. Anais... Fortaleza: Antac, 2008. 1 CDROM. 
MORENO, M. M.; NOGUCHI, E.; LABAKI, L. C. Índice de Conforto Térmico para áreas externas em Clima Tropical De Altitude. In: ENCONTRO NACIONAL DE E V LATINO AMERICANO DE CONFORTO NO AMBIENTE CONSTRUIIDO, 9., Ouro Preto. Anais... Ouro Preto: ANTAC, 2007. CD-ROM.

NIKOLOPOULOU, M. Rediscovering the Urban Realm and Open Spaces - RUROS. Grecia: Centre for Renewable Energy Sources - CRES, 2001. Disponível em: <http://alpha.cres.gr/ruros/>. Acesso em: 3 fev. 2009.

NIKOLOPOULOU, M. Microclimate and Comfort Conditions in Urban Spaces: an intricate relationship. In: PASSIVE AND LOW ENERGY ARCHITECTURE, Toulouse, 2002.

Proceedings... Toulouse: PLEA International, 2002. 1 CD-ROM.

PEIXOTO, M. C.; LABAKI, L. C; SANTOS, R. F. Conforto Térmico nas Cidades: avaliação de efeitos da arborização no controle da radiação solar. In: ENCONTRO NACIONAL SOBRE CONFORTO NO AMBIENTE CONTRUÍDO, Rio de Janeiro, RJ, 1995. Anais... Rio de Janeiro: Antac, 1995. p. 629-634.

PEREIRA, A. R.; ANGELOCCI, L. R.; SENTELHAS, P. C. Agrometeorologia: fundamentos e aplicações práticas. Guaíba: Livraria e Editora Agropecuária, 2002. 478 p.
PEREIRA, A. R.; GREEN, S.; VILLA NOVA, N. A. Penman-Monteith Reference Evapotranspiration Adapted to Estimate Irrigated Tree Transpiration. Agricultural Water

Management, v. 83, p. 153-161, 2006.

PEZZUTO, C. C.; LABAKI, L. C. Conforto Térmico em Espaços Urbanos Abertos: avaliação em áreas de fluxo de pedestres. In: ENCONTRO NACIONAL DE E V LATINO AMERICANO DE CONFORTO NO AMBIENTE CONSTRUÍDO, 9., Ouro Preto, 2007. Anais... Ouro Preto: Antac, 2007. 1 CD-ROM.

PREFEITURA MUNICIPAL DE CAMPINAS. Guia de Arborização Urbana de Campinas. Campinas: Prefeitura, 2007. 69 p.

SANTAMOURIS, M. Energy and Climate in the Urban Built Environment. Londres: James \& James, 2001. 402 p.

SPANGENBERG, J. et al. The Impact of Urban Vegetation on Microclimate in Hot Humid São Paulo. In: PASSIVE AND LOW ENERGY ARCHITECTURE, Singapore, 2007. Proceedings... Singapore: PLEA International, 2007. 1 CD-ROM.

\section{Agradecimentos}

As autoras agradecem à FAPESP, pelo apoio financeiro e bolsa (Processo no 2008/05870-5) para o desenvolvimento desta pesquisa, e também aos técnicos Obadias P. da Silva e Daniel Celente, do Laboratório de Conforto Ambiental e Física (LACAF), da Faculdade de Engenharia Civil, Arquitetura e Urbanismo da Unicamp. 